\title{
Hereditary Spherocytosis in a Middle-aged Man Complicated with Common Bile Duct Stones
}

\author{
Hiroaki Sawahara ${ }^{1}$, Masaya Iwamuro ${ }^{2}$, Ryo Harada ${ }^{1}$, Masao Yoshioka ${ }^{3}$, \\ Takefumi Niguma ${ }^{4}$, Tetsushige Mimura ${ }^{4}$ and Kazuhide Yamamoto ${ }^{1}$
}

\begin{abstract}
Hereditary spherocytosis is the most common form of hemolytic anemia and is characterized by spherical, osmotically fragile erythrocytes that are selectively trapped by the spleen. Hereditary spherocytosis is typically diagnosed in childhood. We herein experienced a rare case of hereditary spherocytosis diagnosed in middle age. The patient presented with cholelithiasis and hyperbilirubinemia. He had no anemia and was asymptomatic with mild splenomegaly. In the differential diagnosis of these symptoms, the possibility of hereditary spherocytosis should be considered, even in patients who are middle-aged and lack anemia.
\end{abstract}

Key words: hereditary spherocytosis, gall bladder stone, splenomegaly

(Intern Med 54: 1509-1512, 2015)

(DOI: 10.2169/internalmedicine.54.4812)

\section{Introduction}

Hereditary spherocytosis is inherited in an autosomal dominant manner and is typically diagnosed in childhood. It occurs in 1 per 50,000-100,000 individuals and is the most common disease causing inherited hemolytic anemia in Japan (1). This disease is characterized by hemolysis due to defects in the red blood cell membrane proteins. The membrane proteins involved include ankyrin, band 3, $\alpha$ spectrin, $\beta$ spectrin, and protein 4.2 . Such defects in the membrane proteins lead to a loss of membrane surface area and the formation of sphere-shaped, malformed red blood cells (2). This deformity makes cells more prone to being disrupted.

The clinical symptoms of patients with this disease are diverse, but often include anemia, jaundice, and splenomegaly. Cholelithiasis resulting from hyperbilirubinemia is also a representative feature of this disease. Generally, these gallstones are found in patients between 10 and 30 years of age $(2,3)$. Thus, the diagnosis of cholelithiasis in a patient's fifth decade is relatively infrequent. We herein report a case of hereditary spherocytosis diagnosed in a patient at 53 years of age. His initial symptoms were episodic jaundice, gall bladder stones, and common bile duct stones. The patient did not exhibit anemia. This case indicates that hereditary spherocytosis should be considered as a possible underlying disease in patients with cholelithiasis and hyperbilirubinemia, even if the patients are middle-aged and lack anemia.

\section{Case Report}

A 53-year-old man underwent magnetic resonance cholangiopancreatography (MRCP) due to elevated levels of indirect bilirubin. The episodic elevation of the indirect bilirubin levels had been detected a few years previously, but the underlying disease had not been determined. Since the existence of common bile duct stones was highly suspected based on the MRCP, the patient was referred to our institution for further investigation and medical treatment.

The patient was asymptomatic. He had a previous surgical history of partial colectomy of the ascending colon due to diverticulosis, but he had had no episode of cholelithiasis. A physical examination revealed only slight conjunctival

\footnotetext{
${ }^{1}$ Department of Gastroenterology and Hepatology, Okayama University Graduate School of Medicine, Dentistry, and Pharmaceutical Sciences, Japan, ${ }^{2}$ Department of General Medicine, Okayama University Graduate School of Medicine, Dentistry, and Pharmaceutical Sciences, Japan, ${ }^{3}$ Department of Internal Medicine, Okayama Saiseikai General Hospital, Japan and ${ }^{4}$ Department of Surgery, Okayama Saiseikai General Hospital, Japan

Received for publication December 25, 2014; Accepted for publication January 18, 2015

Correspondence to Dr. Hiroaki Sawahara, yamairo@hotmail.com
} 


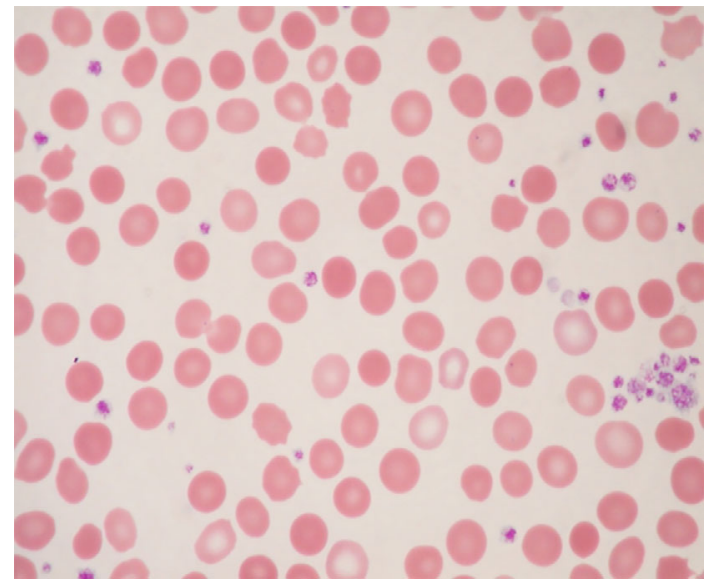

Figure 1. A microscopy image of the peripheral blood smear. Spherocytosis and normocytic normochromic red blood cells with poikilocytosis were seen.

icterus. There was no abdominal pain or tenderness. Routine laboratory tests were performed, and the following results were obtained: white blood cell count, $5,900 / \mu \mathrm{L}$; hemoglobin, $14.8 \mathrm{~g} / \mathrm{dL}$; platelet count, $129,000 / \mu \mathrm{L}$; hematocrit, 40.7\%; mean corpuscular volume, $98.3 \mathrm{fL}$; mean corpuscular volume concentration, $36.4 \mathrm{~g} / \mathrm{dL}$; aspartate transaminase (AST), $31 \mathrm{IU} / \mathrm{L}$; alanine transaminase (ALT), $55 \mathrm{IU} / \mathrm{L}$; total bilirubin, $2.9 \mathrm{mg} / \mathrm{dL}$; direct bilirubin, $0.2 \mathrm{mg} / \mathrm{dL}$; and alkaline phosphatase (ALP), $310 \mathrm{IU} / \mathrm{L}$. An abdominal computed tomography (CT) scan showed several gall bladder stones, common bile duct stones, and splenomegaly. Based on the existence of elevated indirect bilirubin levels, gall bladder stones, and splenomegaly, the patient was suspected to have hemolysis. Further studies revealed the following: the patient's corrected reticulocyte count was $5.4 \%$ and the haptoglobin level was below $10 \mathrm{mg} / \mathrm{dL}$ (normal range, 30-200 $\mathrm{mg} / \mathrm{dL}$ ), but the direct and indirect Coombs' tests were negative. A peripheral blood smear showed spherocytosis and normocytic normochromic red blood cells with poikilocytosis (Fig. 1). An interview to determine his family medical history revealed hereditary spherocytosis in his cousin. Thus, the diagnosis of hereditary spherocytosis was made. After his diagnosis, his niece was examined as well and it was found that she also had hereditary spherocytosis (Fig. 2).

Endoscopic retrograde cholangiopancreatography (ERCP) was performed, and the bile duct stones were extracted (Fig. 3). The color of the extracted stones was black, suggesting that the stones were composed of bilirubin. Subsequently, the patient underwent laparoscopy-assisted cholecystectomy to remove the gall bladder stones and laparoscopic splenectomy to improve hemolytic anemia. After the surgery, the bilirubin levels normalized and remained within the normal ranges, and the reticulocyte count decreased over the next six months. There has been no recurrence of common bile duct stones over the past two years.
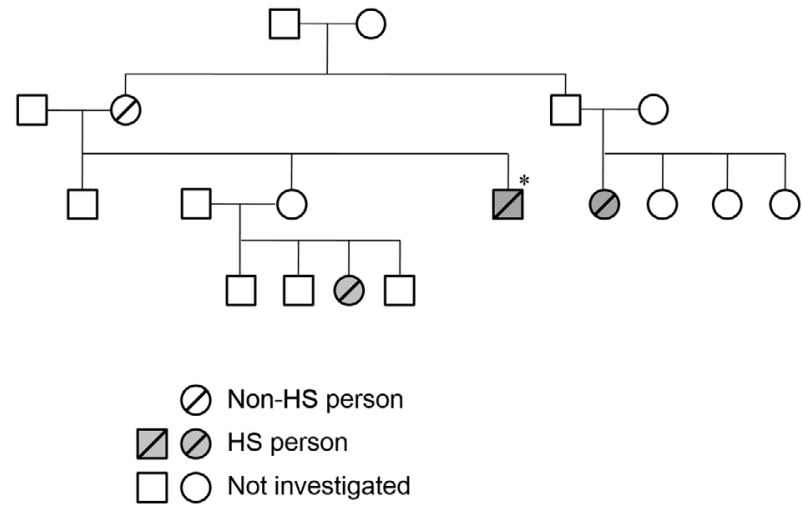

Figure 2. Family pedigree of the present patient. Asterisk (*) indicates the present patient. Squares represent males, and circles represent females. HS: hereditary spherocytosis

\section{Discussion}

The clinical symptoms of patients with hereditary spherocytosis are diverse, ranging from well-compensated hemolytic anemia to profound anemia requiring frequent blood transfusions (2, 4). Approximately $60-70 \%$ of patients have moderate disease, showing a slight decrease in hemoglobin (>8 g/dL) and moderately elevated levels of reticulocytes and bilirubin (2). These patients are typically diagnosed in childhood. Overall, more than $75 \%$ of hereditary spherocytosis patients have been diagnosed before 11 years of age (5). Conversely, approximately $20-30 \%$ of patients present with mild disease. In these patients, hemolysis is compensated for, resulting in an absence of anemia with mild splenomegaly, slight reticulocytosis, and bilirubinemia (6). The diagnosis of hereditary spherocytosis is delayed until adulthood in these patients because of the asymptomatic course, as presented in this case report. Our patient had mild bilirubinemia for a few years, but he had no other manifestations, and his underlying disease was not determinable until he underwent MRCP. In patients with mild disease, the initial symptoms or clues leading to the diagnosis of hereditary spherocytosis include cholelithiasis, splenomegaly, anemia due to a viral infection such as parvovirus B19 or influenza, and assessment of the family history $(2,7,8)$.

The formation of gallstones is the most common complication of hereditary spherocytosis. Chronic hemolysis of red blood cells leads to increased indirect bilirubin levels and the formation of gallstones. These gallstones are composed of calcium bilirubinate, which gives the stones a brown to black pigment. It has been reported that patients with hereditary spherocytosis and co-inherited Gilbert's syndrome have a four- to five-fold increased risk of cholelithiasis compared to patients with hereditary spherocytosis alone (2, 9-13). Gilbert's syndrome causes hyperbilirubinemia due to the diminished activity of the conjugating enzyme uridine diphosphate-glucuronyltransferase (UGT1A1). Gilbert's syndrome, the most common form of familial unconjugated hyperbilirubinemia, can be found in $5-10 \%$ of 

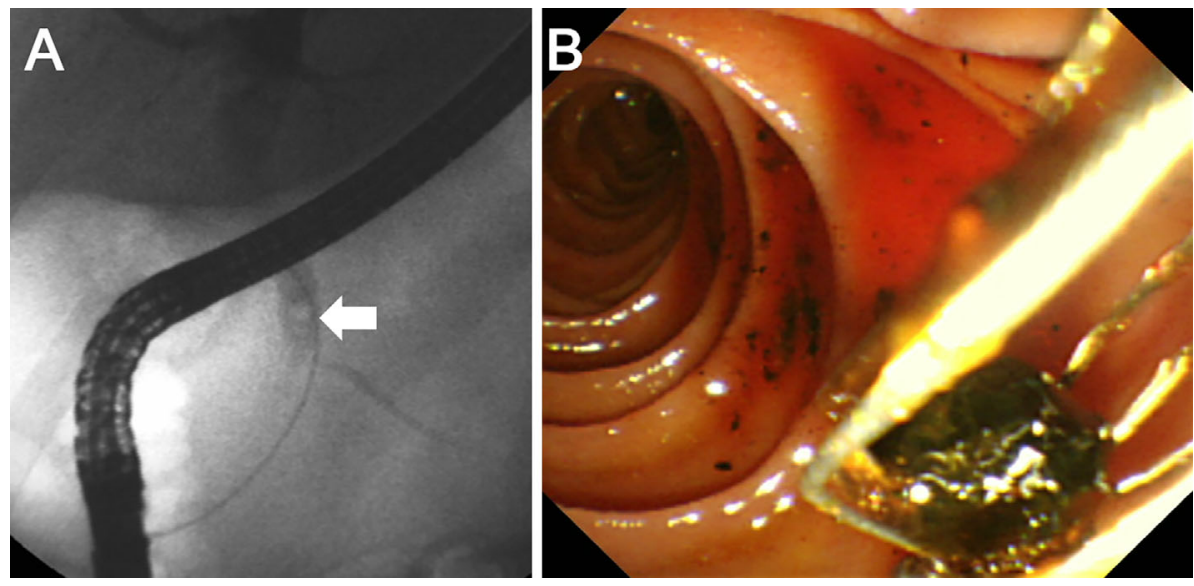

Figure 3. Endoscopic retrograde cholangiopancreatography images. After the injection of the contrast medium, multiple filling defects were visualized in the lower common bile duct (A, arrow). Bile duct stones were extracted with a basket catheter $(B)$. The color of the extracted stones was black, suggesting that the stones were composed of bilirubin.

Caucasians (14). Although there is no biological correlation between hereditary spherocytosis and Gilbert's syndrome, it is possible that both diseases concomitantly occur in a considerable number of patients because of the high incidence rate of both diseases (15). Thus, the number of cases actually diagnosed may understate the actual prevalence of each disease. In the present case, the possibility of the coexistence of Gilbert's syndrome cannot be excluded, although the UGT1A1 genotype was not examined.

The surgical removal of the spleen is the treatment of choice for patients with moderate-to-severe hemolysis, because abnormal spherocytes are trapped and destroyed mainly in the spleen. Splenectomy leads to an increased red cell life span, a decreased transfusion requirement, and a decreased incidence of gall bladder stones $(2,16)$. Recent advancements in laparoscopic surgery techniques allow surgeons to safely perform splenectomy under a laparoscope $(2,17-19)$. The laparoscopic approach to splenectomy is recommended in the latest version of the guidelines for the diagnosis and management of hereditary spherocytosis (20). In the present case, the patient underwent laparoscopic splenectomy and laparoscopic-assisted cholecystectomy.

In summary, we experienced a case of hereditary spherocytosis which was diagnosed in middle age. This case underscores the importance of including hereditary spherocytosis in the differential diagnosis when patients present with cholelithiasis and hyperbilirubinemia, even if the patients are middle-aged and/or lack symptoms of anemia.

The authors state that they have no Conflict of Interest (COI).

\section{References}

1. Shibuya A. Congenital hemolytic anemia. Shonika Rinsho (Japanese Journal of Pediatrics) 62: 321-328, 2009 (in Japanese).

2. Perrotta S, Gallagher PG, Mohandas N. Hereditary spherocytosis.
Lancet 372: 1411-1426, 2008.

3. Tamary H, Aviner S, Freud E, et al. High incidence of early cholelithiasis detected by ultrasonography in children and young adults with hereditary spherocytosis. J Pediatr Hematol Oncol 25: 952-954, 2003.

4. Ruparel RK, Bogert JN, Mori CR, et al. Synchronous splenectomy during cholecystectomy for hereditary spherocytosis: is it really necessary? J Pediatr Surg 49: 433-435, 2014.

5. Krueger HC, Burgert EO Jr. Hereditary spherocytosis in 100 children. Mayo Clin Proc 41: 821-830, 1966.

6. Guarnone R, Centenara E, Zappa M, Zanella A, Barosi G. Erythropoietin production and erythropoiesis in compensated and anaemic states of hereditary spherocytosis. $\mathrm{Br} \mathrm{J}$ Haematol 92: 150-154, 1996.

7. Eber S, Lux SE. Hereditary spherocytosis: defects in proteins that connect the membrane skeleton to the lipid bilayer. Semin Hematol 41: 118-141, 2004.

8. Jensson O, Jónasson JL, Magnússon S. Studies on hereditary spherocytosis in Iceland. Acta Med Scand 201: 187-195, 1977.

9. del Giudice EM, Perrotta S, Nobili B, Specchia C, d'Urzo G, Iolascon A. Coinheritance of Gilbert syndrome increases the risk for developing gallstone in patients with hereditary spherocytosis. Blood 94: 2259-2262, 1999.

10. Berk PD, Blaschke TF. Detection of Gilbert's syndrome in patients with hereditary spherocytosis. Ann Intern Med 77: 527, 1972.

11. Katz ME, Weinstein IM. Extreme hyperbilirubinemia in a patient with hereditary spherocytosis, Gilbert's syndrome and obstructive jaundice. Am J Med Sci 275: 373, 1978.

12. Sharma S, Vukeljia SJ, Kadakia S. Gilbert's syndrome co-existing with and masking hereditary spherocytosis. Ann Hematol 74: 287289, 1997.

13. Iolascon A, Faienza MF, Moretti A, Perrotta S, Miraglia del Giudice E. UGT1 promoter polymorphism accounts for increased neonatal appearence of hereditary spherocytosis. Blood 91: 1093, 1998.

14. Owens D, Evans J. Population studies on Gilbert's syndrome. J Med Genet 12: 152-156, 1975.

15. Lee MJ, Chang YH, Kang SH, et al. A case of hereditary spherocytosis coexisting with Gilbert's syndrome. Korean J Gastroenterol 61: 166-169, 2013.

16. Bader-Meunier B, Gauthier F, Archambaud F, et al. Long-term evaluation of the beneficial effect of subtotal splenectomy for 
management of hereditary spherocytosis. Blood 97: 399-403, 2001.

17. Farah RA, Rogers ZR, Thompson WR, Hicks BA, Guzzetta PC Buchanan GR. Comparison of laparoscopic and open splenectomy in children with hematologic disorders. J Pediatr 131: 41-46, 1997.

18. Rescorla FJ, West KW, Engum SA, Grosfeld JL. Laparoscopic splenic procedures in children: experience in 231 children. Ann
Surg 246: 683-687, 2007.

19. Rescorla FJ, Engum SA, West KW, Tres Scherer LR III, Rouse TM, Grosfeld JL. Laparoscopic splenectomy has become the gold standard in children. Am Surg 68: 297-301, 2002.

20. Bolton-Maggs PH, Langer JC, Iolascon A, Tittensor P, King MJ. Guidelines for the diagnosis and management of hereditary spherocytosis: 2011 update. Br J Haematol 156: 37-49, 2012.

(C) 2015 The Japanese Society of Internal Medicine http://www.naika.or.jp/imonline/index.html 